\title{
Unusual and intraoperative epicardial echocardiographic features of a papillary tumour of the aortic valve
}

\author{
NEIL P LEWIS, GERAINT T WILLIAMS, * ALAN G FRASER \\ From the Departments of Cardiology and ${ }^{\star}$ Pathology, University Hospital of Wales, Heath Park, Cardiff
}

SUMMARY A mass with a diameter of $0.8 \mathrm{~cm}$ was detected in the aortic root of a 53 year old woman during routine preoperative cross sectional echocardiographic assessment of a secundum atrial ${ }_{0}$ septal defect. Intraoperative epicardial echocardiography showed that the mass was attached by a을 slender stalk to the tip of the left coronary cusp of the aortic valve, and histological examination showed that it was a papillary tumour.

Intraoperative epicardial echocardiography can help in planning the excision of papillary tumours, and excision is advised even when there are no symptoms.

Papillary tumours of the heart are uncommon. Until recently, they were diagnosed only as an incidental finding at necropsy, ${ }^{1}$ but now they can be detected more frequently by cross sectional echocardiography ${ }^{2}$ or recognised during cardiac operation. ${ }^{3}$ The aetiology of papillary tumours is uncertain. These lesions are not always asymptomatic and they need to be diagnosed accurately and distinguished from other conditions such as vegetations caused by infective endocarditis, which are managed differently.

There has been only one previous report of the cross sectional echocardiographic diagnosis of a papillary tumour arising from the aortic valve $e^{4}$ in another patient who had $\mathbf{M}$ mode echocardiography alone, the features were thought to suggest infective endocarditis and the diagnosis was not established until operation. ${ }^{5}$ We describe the preoperative and intraoperative epicardial echocardiographic features of a papillary tumour of the aortic valve.

\section{Case report}

A 53 year old woman reported dyspnoea on exertion for two years. She had no other symptoms, and in particular no history of chest pain or episodes suggestive of systemic embolism. On examination, the pulse was regular and the blood pressure and venous pressure were normal. There was a mild

Requests for reprints to Dr Neil P Lewis, Department of Cardiology, University Hospital of Wales, Heath Park, Cardiff CF4 4XN. parasternal lift, fixed splitting of the second heart $\vec{\oplus}$ sound, and an ejection systolic murmur over the pulmonary area.

The electrocardiogram showed sinus rhythm, complete right bundle branch block, and a normal cardiac axis. The chest radiograph showed mild cardiomegaly, an enlarged main pulmonary artery, and pulmonary plethora. Routine haematological and biochemical tests and urine analysis and culture were normal. Blood cultures yielded no growth. The erythrocyte sedimentation rate was $13 \mathrm{~mm}$ in the first hour.

Echocardiography was performed with a Hewlett Packard duplex system. The right ventricle was enlarged (diastolic and systolic dimensions from $M$ mode 3.7 and $2.9 \mathrm{~cm}$ ) and there was paradoxical motion of the interventricular septum. Cross sectional imaging showed an ostium secundum atrial septal defect, and a mass in the aortic root that was featureless, round, and $0.8 \mathrm{~cm}$ in diameter (area $1.5 \mathrm{~cm}^{2}$ ). It was seen well in both parasternal long axis and short axis planes, in the region of the $N$ commissure between the right and left coronary cusps of the aortic valve (fig 1a,b). The mass was not 0 apparent on most $M$ mode recordings of the aortic $\omega$ valve. There was no aortic regurgitation. The mass was thought to be a myxoma, although a vegetation 0 (and thus infective endocarditis) could not be $\mathbb{\Phi}$ excluded.

Cardiac catheterisation also confirmed that the patient had an atrial septal defect. The pulmonary to systemic flow ratio was 3:1, and the pulmonary artery pressure was $50 / 15 \mathrm{~mm} \mathrm{Hg}$. Neither left ven- 


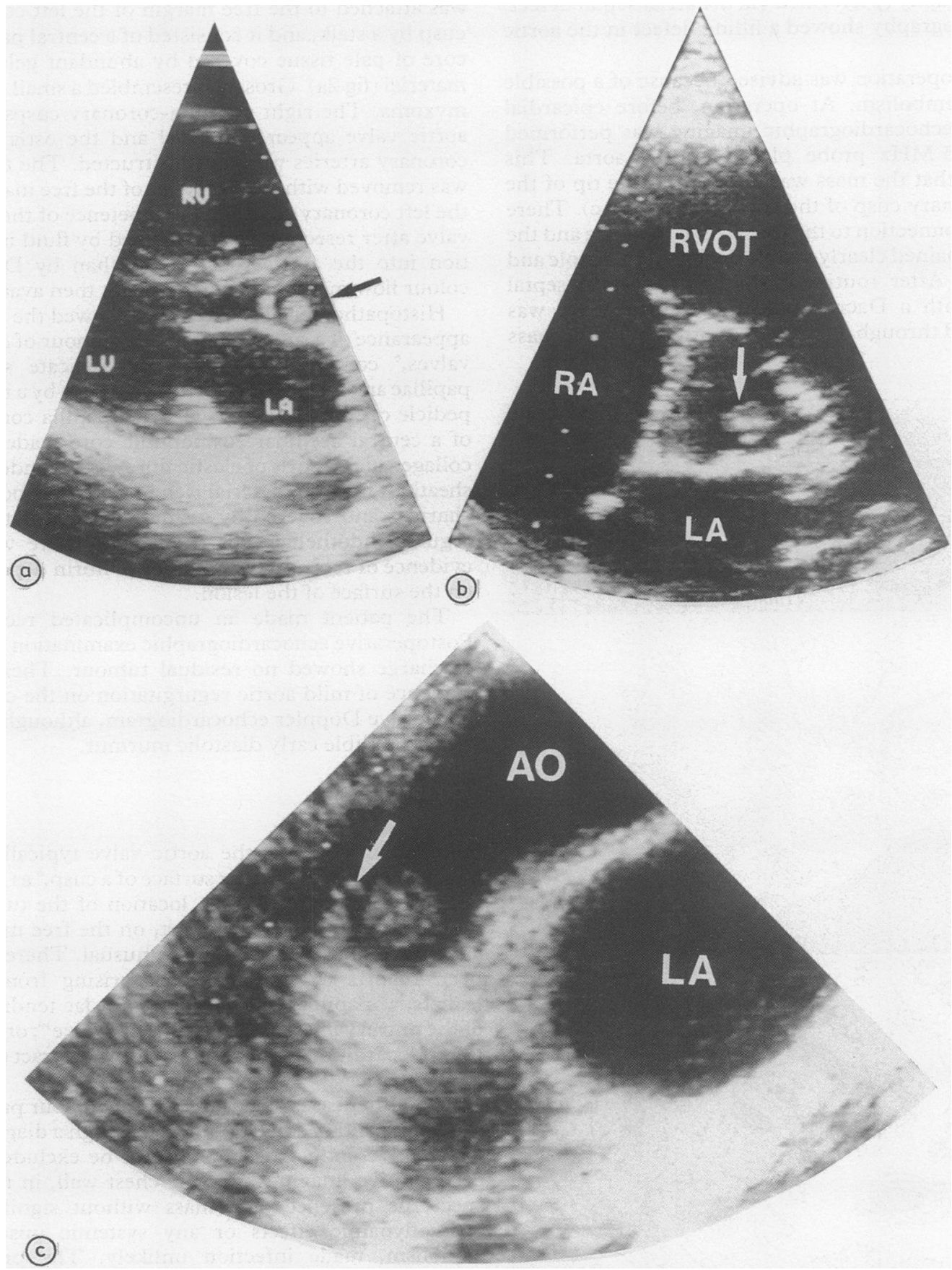

Fig 1 Cross sectional echocardiographic images showing spherical mass (arrowed) in the aortic root. (a) Parasternal long axis view showing mass in the posterior half of the aortic root. (b) Short axis view showing mass between right and left coronary cusps. $L V$, left ventricle; $L A$, left atrium; $R V$, right ventricle; $R V O T, R V$ outflow tract; $R A$, right atrium. (c) Intraoperative epicardial echocardiogram showing attachment of the mass by a stalk (arrowed) to the top of the left coronary cusp. AO, ascending aorta; $L A$, left atrium. 
triculography (performed via the atrial septal defect) nor aortography showed a filling defect in the aortic root.

Early operation was advised because of a possible risk of embolism. At operation, before epicardial bypass, echocardiographic imaging was performed with a $5 \mathrm{MHz}$ probe placed on the aorta. This showed that the mass was attached to the tip of the left coronary cusp of the aortic valve (fig 1c). There was no connection to the free wall of the aorta and the mass remained clearly visible during both systole and diastole. After routine closure of the atrial septal defect with a Dacron patch, the aortic valve was examined through a transverse aortotomy. The mass

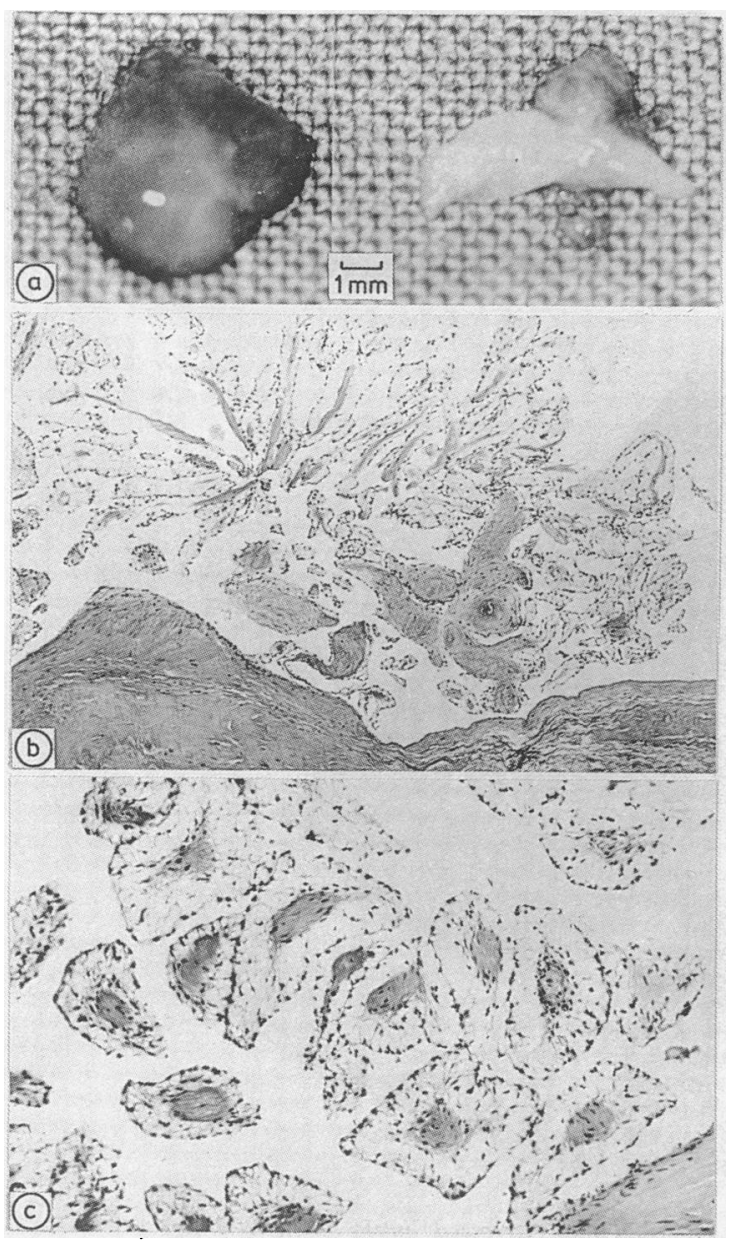

Fig 2 (a) Large fragment of the papillary tumour mass and the excised edge of the aortic leaflet showing the attached origin of the stalk. (b) Microscopic appearance of the tumour (original magnification $\times 50$ ). (c) Microscopic appearance of the tumour (original magnification $\times 130$ ). was attached to the free margin of the left coronary cusp by a stalk, and it consisted of a central papillary core of pale tissue covered by abundant gelatinous material (fig 2a). Grossly it resembled a small cardiac myxoma. The right and non-coronary cusps of the aortic valve appeared normal and the ostia of the coronary arteries were not obstructed. The tumour was removed with a small sliver of the free margin of the left coronary cusp. The competence of the aortic valve after resection was confirmed by fluid instillation into the aortic root, rather than by Doppler colour flow mapping, which was not then available.

Histopathological examination showed the typical appearance of a so-called papillary tumour of cardiac valves, ${ }^{6}$ composed of numerous delicate slender papillae anchored to the aortic valve cusp by a narrow pedicle of fibroelastic tissue. Each papilla consisted of a central acellular eosinophilic core made up of collagen and whorls of elastic fibres, surrounded by a sheath of myxoid material rich in acid mucopolysaccharides and covered by a single layer of flattened, regular endothelial cells (fig $2 b, c$ ). There was no evidence of recent thrombosis or of fibrin deposition on the surface of the lesion.

The patient made an uncomplicated recovery. Postoperative echocardiographic examination before discharge showed no residual tumour. There was evidence of mild aortic regurgitation on the continuous wave Doppler echocardiogram, although there was no audible early diastolic murmur.

\section{Discussion}

Papillary tumours of the aortic valve typically are attached to the ventricular surface of a cusp, ${ }^{6}$ as in the patient of Shub et al. ${ }^{4}$ The location of the tumour described in the present report, on the free margin and aortic surface, is therefore unusual. There have been reports of similar lesions arising from the leaflets, ${ }^{278}$ papillary muscles, ${ }^{9}$ or chordae tendineae ${ }^{4}$ of the mitral valve; from the tricuspid valve ${ }^{10}$; or from the endocardium of the septum or outflow tract of the left ventricle. ${ }^{11-13}$

As in other cases, echocardiography in our patient showed a solitary small nodule. Although a diagnosis of infective endocarditis could not be excluded on preoperative imaging from the chest wall, in retrospect the presence of a mass without significant haemodynamic effects or any systemic upset or embolism, made infection unlikely. The precise attachment of the tumour could not be determined from a parasternal approach-as in a previous case in which echocardiography suggested that a papillary tumour was attached to the anterior mitral leaflet when it was in fact attached only to the chordae tendineae 4 -and therefore intraoperative epicardial 
imaging was very helpful. The clarity of epicardial echocardiographic images may be of particular value where transthoracic images are of poor quality. In our case, epicardial echocardiography showed the stalk of the tumour and excluded other lesions such as aortic root abscess associated with infective endocarditis. It also assisted the surgeon in planning the careful excision of the tumour. In one previous case, transoesophageal echocardiography was used during cardiac operation to examine a papillary tumour arising from the anterior leaflet of the mitral valve. ${ }^{8}$ Although no new features were identified on that occasion, intraoperative echocardiography should facilitate more precise diagnosis of a papillary tumour and when allied to colour flow mapping will provide rapid assessment of valve function after excision and valve repair. The images obtained from epicardial and transoesophageal echocardiography are of similar quality, so that the ideal intraoperative technique will depend in part on the anatomical location of each tumour. Epicardial imaging in a sterile operative field can be easily achieved by enclosing the imaging probe in a sterile plastic bag. The ease and convenience of this approach may lead to epicardial imaging becoming the more popular form of intraoperative echocardiography particularly if, as is already practised in some centres, surgeons become familiar with the use of echocardiographic equipment themselves. ${ }^{14}$

In seven out of 12 (including our patient) echocardiographic reports of papillary tumours $M$ mode traces have been normal. Nevertheless, additional echoes have sometimes been seen on the aortic valve, ${ }^{5}$ on the anterior mitral leaflet, ${ }^{4}$ in the left ventricular outflow tract, ${ }^{13}$ or on the tricuspid valve. ${ }^{10}$

The aetiology of papillary tumours is unclear, and this is reflected by the variety of names (at least 16) by which they are known. ${ }^{7813}$ In some journals current usage favours the term "fibroelastoma", but until the cause and nature of these lesions are established, we prefer to continue to use the simplest descriptive term, namely papillary tumour. ${ }^{6}$ Most cases reported by pathologists occurred in the elderly or in patients with chronic valvitis, ${ }^{16}$ but in recent years there have been several reports of papillary tumours in patients with a history of previous cardiac operation..$^{1014}$ In another ${ }^{-}$patient, several papillary tumours were detected within the left ventricle, eight years after a septal myectomy had been performed. ${ }^{5}$ Such cases seem to support the observation that the histological features of papillary tumours are not those of true neoplasms but resemble so-called giant Lambl's excrescences-lesions tht are thought to arise by the organisation of small deposits of fibrin at the sites of minor endothelial damage. ${ }^{6}$ It is hard to understand, however, how such a process could give rise to a mass almost $1 \mathrm{~cm}$ in diameter, as in our patient, without that mass becoming detached. Some have suggested that both papillary tumours and cardiac myxomas originate from organising mural thrombus, ${ }^{615}$ because papillary tumours have abundant extracellular acid mucopolysaccharides and a gelatinous consistency similar to that of cardiac myxomas, but this view is at odds with more recent reports of chromosomal abnormalities, ${ }^{16}$ abnormal cell differentiation, ${ }^{17}$ and neuroendocrine components ${ }^{18}$ in myxomas.

Whatever their aetiology, large papillary tumours should probably be removed, even when they are found incidentally during investigations for an unrelated illness, as in our patient. Papillary tumours of the aortic valve in particular have been reported to cause angina ${ }^{1920}$ or death, ${ }^{20-23}$ presumably from occlusion of a coronary ostium. Tumours in the left ventricle and on the mitral valve have been associated with recurrent systemic emboli and neurological problems ${ }^{7812}$ and myocardial infarction in a patient with angiographically normal coronary arteries. ${ }^{7}$ Systemic embolisation was rarely reported before 1971 (it occurred in three of 39 cases reviewed by Fowles et $a l^{2}$ ), but it is more likely that papillary tumours are now being discovered increasingly by echocardiography than that they are being incriminated erroneously as a source of emboli. In two patients thrombus was found on the surface of the tumour on histological examination, ${ }^{27}$ so anticoagulation should be considered pending surgery. At operation it is usually possible to perform a simple excision of the tumour with conservation, ${ }^{10}$ as in our patient, or repair ${ }^{28}$ of the related valve. There have been no reports of recurrence of a papillary tumour, but echocardiographic surveillance is advisable.

We thank Mr E G Butchart, FRCS, for his help with this patient.

\section{References}

1 Abu Nassar SG, Parker JC. Incidental papillary endocardial tumor. Its potential significance. Arch Pathol 1971;92:370-6.

2 McFadden PM, Lacy JR. Intracardiac papillary fibrolastoma: an occult cause of embolic neurological deficit. Ann Thorac Surg 1987;43:667-9.

3 Lichtenstein HL, Lee JCK, Stewart S. Papillary tumor of the heart: incidental finding at surgery. Hum Pathol 1979;10:473-5.

4 Shub C, Tajik AJ, Seward JB, et al. Cardiac papillary fibroelastomas. Two-dimensional echocardiographic recognition. Mayo Clin Proc 1981;56:629-33.

5 Levinsky L, Srinivasan V, Gingell RL, et al. Papillary fibroelastoma of aortic and mitral valves following 
myectomy for idiopathic hypertrophic subaortic stenosis. Thorac Cardiovasc Surg 1981;29:187-91.

6 Pomerance A. Papillary "tumours" of the heart valves. $J$ Pathol Bacteriol 1981;81:135-40.

7 Fowles RE, Miller DC, Egbert BM, Fitzgerald JW, Popp RL. Systemic embolization from a mitral valve papillary endocardial fibroma detected by twodimensional echocardiography. Am Heart J 1981; 102:128-30.

8 Topol EJ, Biern RO, Reitz BA. Cardiac papillary fibroelastoma and stroke. Echocardiographic diagnosis and guide to excision. Am J Med 1986;80: 129-32.

9 Cha SD, Incarvito J, Fernandez J, Chang KS, Maranhao VM, Gooch AS. Giant Lambl's excrescences of papillary muscle and aortic valve: echocardiographic, angiographic and pathologic findings. Clin Cardiol 1981;4:51-4.

10 Frumin H, O'Donnell L, Kerin NZ, Levine F, Nathan LE, Klein SP. Two-dimensional echocardiographic detection and diagnostic features of tricuspid papillary fibroelastoma. J Am Coll Cardiol 1983;2:1016-8.

11 Flotte T, Pinar H, Feiner H. Papillary elastofibroma of the left ventricular septum. Am J Surg Pathol 1980; 4:585-8.

12 Ong LS, Nanda NC, Barold SS. Two-dimensional echocardiography detection and diagnostic features of left ventricular papillary fibroelastoma. Am Heart J 1986;103:917-8.

13 Almagro UA, Perry LS,Choi H, Pintar K. Papillary fibroelastoma of the heart. Report of six cases. Arch Pathol Lab Med 1982;106:318-21.
14 Fraser AG, van Herwerden L, van Daele MERM, Bos $C$ E, Roelandt JRTC, Sutherland GR. The relative $\vec{F}$ values of intraoperative epicardial and transoeso- $\stackrel{S}{\rightarrow}$ phageal echocardiography in mitral valve repair [Abstract]. Br Heart J 1989;61:451.

15 Heath D, Thompson I McK. Papillary "tumours" of the left ventricle. Br Heart J 1965;29:950-4.

16 Salyer WR, Page DL, Hutchins GM. The development of cardiac myxomas and papillary endocardial lesions from mural thrombus. Am Heart J 1975;89:4-17.

17 Dewald GW, Dahl RJ, Spurbeck JL, Carney JA, Gordon H. Chromosomally abnormal clones and $\vec{\omega}$ nonrandom telomeric translocations in cardiac myxomas. Mayo Clin Proc 1987;62:558-67.

18 Goldman BI, Frydman C, Harpaz N, Ryan SF, Loiterman D. Glandular cardiac myxomas. Histologic, oimmunohistochemical, and ultrastructural evidence of epithelial differentiation.Cancer 1987;59:1767-75.

19 Davies MJ, Rode J, Woolf N, Krikler DM. Neuroendocine differentiation in atrial myxomas. Lancet 1987;ii:800.

20 Heath D, Best PV, Davis BT. Papilliferous tumours of the heart valves. Br Heart J 1961;23:20-4.

21 Rona G, Feeney N, Kahn DS. Fibroelastic hamartoma of the aortic valve producing ischemic heart disease. Associated pulmonary globus bodies. Am J Cardiol 1983;12:869-74.

22 Harris LS, Adelson L. Fatal coronary embolism from a myxomatous polyp of the aortic valve. Am J Clin Pathol 1965;43:61-4.

23 Butterworth JS, Poindexter CA. Papilloma of cusp of the aortic valve. Report of a patient with sudden death. Circulation 1973;48:213-5. 